\title{
Spatial and Temporal Dynamics of Invasive Freshwater Shrimp (Mysis diluviana): Long-Term Effects on Ecosystem Properties in a Large Oligotrophic Lake
}

\author{
Shawn P. Devlin, ${ }^{1}$ Samantha K. Tappenbeck, ${ }^{1}$ James A. Craft, ${ }^{1}$ \\ Tyler H. Tappenbeck, ${ }^{1}$ Dale W. Chess, ${ }^{2}$ Diane C. Whited, ${ }^{1}$ Bonnie K. Ellis, ${ }^{1}$ \\ and Jack A. Stanford ${ }^{1 *}$
}

${ }^{1}$ Flathead Lake Biological Station, The University of Montana, 32125 Bio Station Lane, Polson, Montana 59860, USA; ${ }^{2}$ Coeur d'Alene Tribe, Lake Management, 401 Anne Antelope Road, Plummer, Idaho 83851, USA

\begin{abstract}
Invasion of Mysis diluviana from upstream stockings drastically altered the food web of $480 \mathrm{~km}^{2}$ Flathead Lake, Montana (USA). Mysis increased exponentially after establishment in 1982, preying upon large zooplankters, thereby substantially altering zooplankton community composition, favoring small-sized species. In consequence, primary production increased by $21 \%$ owing to changes in zooplankton feeding efficiency. Moreover, the abundant Mysis provided forage for the nonnative lake trout that also rapidly expanded, causing concomitant extirpation of kokanee salmon and near loss of native fishes. This has become a case history of how introduced species can mediate trophic cascades. Here we examine the long-term (1982-2014) dynamics of Mysis in Flathead Lake and how distribution and
\end{abstract}

Received 21 March 2016; accepted 16 June 2016; published online 31 August 2016

Electronic supplementary material: The online version of this article (doi:10.1007/s10021-016-0023-x) contains supplementary material, which is available to authorized users.

Author contributions This study was designed by BE, DC, and JS. Field and laboratory data were obtained by JC, ST, TT, and DC. DW conducted the geospatial analysis. ST and SD conducted the statistical analyses. SD, ST and JS wrote the paper with input from all co-authors. The study was funded by a grant to BE.

*Corresponding author; e-mail: jack.stanford@umontana.edu abundance of this invasive species is related to chemical, physical, and biological factors. We show that Mysis is a strong interactor, regulating zooplankton and phytoplankton biomass interactively with nutrient ( $\mathrm{N}$ and $\mathrm{P}$ ) dynamics. Moreover, changes in life history and changing spatial dynamics are strengthening the regulatory role of the Mysis, despite seemingly strong top-down pressure via predation of the Mysis by lake trout. The Mysis are structuring nearly all interactions within and between the biota of Flathead Lake.

Key words: food web; trophic cascade; Mysis diluviana; strong interactor; Flathead Lake; lake trout; long-term limnological data; ecosystem regulation.

\section{INTRODUCTION}

Introductions of nonnative species to aquatic systems have led to profound changes to native food webs, often with unintended results (Li and Moyle 1981). During the mid-twentieth century, Mysis diluviana, (formerly $M$. relicta Lóven and herein 
Mysis) was introduced to nonnative lakes across the Nearctic region in an effort to enhance fisheries. The native range of Mysis is northern circumpolar in deep, very oligotrophic lakes (Pennak 1989). One of the first nonnative lakes in North America to receive Mysis was Kootenay Lake, British Columbia, Canada, in an effort to enhance salmonid fisheries. Following immigration from stocked lakes in the upper catchment, Mysis was first detected in Flathead Lake (northwest Montana, USA) in 1982. The population reached a maximum density in 1986 that coincided with the unintended collapse of the kokanee salmon (Oncorhynchus nerka) fishery, among other food web changes (Ellis and others 2011).

The introduction of Mysis ultimately caused a powerful trophic cascade through the Flathead Lake food web that extended into the contiguous river and terrestrial ecosystems (Ellis and others 2011; Spencer 1991). Establishment of Mysis as the dominant zooplanktivore drove a shift in the structure of the zooplankton community from dominance by large Cladocera to small copepod and rotifer species. Concurrent reduction in algal grazing led to a $21 \%$ increase in primary production. Also, the abundant Mysis alleviated a recruitment bottleneck by providing a deep-water food source for juvenile bottom-dwelling lake trout (Salvelinus namaycush) and Lake whitefish (Coregonus clupeaformis). Direct competition for zooplankton, in combination with intense predation by now-abundant adult piscivorous fishes in the pelagic zone led to the extirpation of zooplanktivorous kokanee salmon (Oncorhynchus nerka); native westslope cutthroat (Oncorhynchus clarkii lewisi) and native bull trout (Salvelinus confluentus) have declined likely also due to predation of juveniles by the lake trout. Thus, establishment and persistence of Mysis has redirected the flow of energy through the food web in Flathead Lake shifting from a pelagic to a profundal-benthic pathway (Ellis and others 2011).

The unique ability of Mysis to successfully propagate, persist, and alter the Flathead Lake food web reflects its evolution in large, deep, cold, and lowproductivity lakes, like Waterton Lake, a Canadian Shield lake in Alberta, Canada. Mysis are omnivorous, feeding primarily on detritus and algae as juveniles, and switching to zooplankton (primarily Cladocera) during subadult and adult life stages (Chess and Stanford 1998). Mysis is a nocturnal species that exhibits diel vertical migration (DVM) through the water column (Beeton 1960; Beeton and Bowers 1982). DVM is primarily influenced by light (Teraguchi and others 1975) and temperature
(Beeton and Bowers 1982), although response to these cues likely evolved as mechanisms to reduce predation and increase food intake (Boscarino and others 2007; Gal and others 2004). Mysis migrates diurnally, feeding at night in warmer water where prey densities are high but energy conversion efficiency is low, and migrates to cold, bottom water during the day where metabolic efficiency is high (Chess and Stanford 1999). This migratory behavior facilitates flexibility in habitat utilization that likely contributes to the success of Mysis in Flathead Lake.

Life history flexibility by Mysis also is a factor in their success as invaders (Beeton and Gannon 1991; Chess and Stanford 1998); the life cycle varies from 1 to 4 years in different lakes (Morgan 1980; Kjellberg and others 1991). Trophic status and length of establishment after invasion have been shown to influence Mysis time to maturity (Fürst 1972; Morgan 1980). Temperature and climate can also influence breeding cycles of Mysis (Lasenby and Langford 1972). Additionally, the timing of brood release influences maturation rates; neonates released in early spring (April-early May) reach maturity the same year, whereas neonates released later remain immature until the following spring (Hakala 1978). In Flathead Lake, time to maturity may vary, and size-frequency data suggest that one or two cohorts per year may occur (Chess and Stanford 1998).

Moreover, both bottom-up (for example, resource and prey availability) and top-down (predation pressure) controls have been shown to influence the abundance and life history patterns of Mysis in native and introduced lakes. Availability of food resources at multiple trophic levels (Schindler and others 2012) and predation pressure (Johannsson and others 2011; Kjellberg and others 1991) influence mysid growth rates and abundance. Additionally, physical conditions such as depth and temperature influence densities and distribution (Berrill and Lasenby 1983). Abundance generally increases with depth and is low to nonexistent in waters less than $25 \mathrm{~m}$ in depth (Carpenter and others 1974), because Mysis habitually avoids warmer surface waters and adults are more common at depth (Chess and Stanford 1998). Age distribution with depth may be caused by resource availability for juvenile growth and intraspecific competition, size-selective predation by planktivorous fishes in the pelagic zone, or it may be that juvenile Mysis exhibit reduced sensitivity to light and temperature relative to adults (Boscarino and others 2010). In Flathead Lake, the cladoceran, Daphnia thorata, is a primary food re- 
source for subadult and adult Mysis; this large cladoceran reaches peak densities from mid-July through early October with abundances greatest in the epilimnion, which the Mysis avoid (Chess and Stanford 1998; our data given below). Nonetheless, the fastest growth rates for Mysis previously reported were observed July through October (Chess and Stanford 1998), despite the potential thermal refugium for $D$. thorata. Likely, the cladocerans descend into the area of the chlorophyll maximum just below the thermocline where the Mysis prey upon them heavily at night. In addition, wind and waves are common on Flathead Lake which often destabilizes the thermocline potentially mixing cladocerans with the Mysis. In any case, given the life history characteristics and plasticity observed in Mysis, it is likely that both bottom-up and top-down trophic interactions, coupled with lake circulation and thermal patterns, mediate annual abundance and spatial distributions (Ellis and others 2011).

The period of record over which Ellis and others (Beattie and Clancy 1991; Ellis and others 2011) documented the cascading trophic effects of Mysis establishment in Flathead Lake encompassed preand post-mysid periods up to 2005. Over the next decade (2005-2014), we observed an increasingly erratic and variable trend in mean annual abundance in time and space. Here we examined the 32year record of Mysis abundance and spatial distribution in relation to biophysical (limnological) factors in Flathead Lake. We examine how population dynamics, life cycles, and spatial distributions of the Mysis have changed over the years since invasion. These interpretations are directly relevant to a more robust understanding of how Mysis function as strong interactors in large lake food webs. The results have strong implications for ongoing management actions to reduce lake trout abundance to conserve native fishes as well as nutrient cycling and associated consequences for long-term water quality in Flathead Lake and the many other north temperate lakes where Mysis has been introduced.

\section{Methods}

\section{Study Site}

Flathead Lake is a glacially modified graben or fault-block lake located in northwest Montana, USA (Figure 1). This large $\left(500 \mathrm{~km}^{2}\right)$ oligotrophic lake is fed by the $22,241 \mathrm{~km}^{2}$ watershed of the Flathead (mean discharge $279 \mathrm{~m}^{-3} \mathrm{~s}^{-1}$ ) and Swan (mean discharge $33 \mathrm{~m}^{3} \mathrm{~s}^{-1}$ ) Rivers (mean lake residence time 2.2 years). Flathead Lake is deep (mean depth $44 \mathrm{~m}$, maximum depth $116 \mathrm{~m}$ ): $48 \%$ of the volume is $0-40 \mathrm{~m}, 30 \%$ is $40-75 \mathrm{~m}$, and $22 \%$ is greater than $75 \mathrm{~m}$ in depth. Long-term monitoring of the biological, chemical, and physical properties of Flathead Lake has been conducted at the deepest point near the middle of the lake (Midlake Deep, MLD; depth 104 m, see Figure 1).

\section{Mysis Surveys}

Mysis were expected to immigrate downstream from Swan or Whitefish Lakes into Flathead Lake, so net hauls were made at the MLD site starting in 1982 to document the initiation of invasion. The first few specimens were caught in 1983 with numbers per square meter of lake surface increasing rapidly thereafter. In 1987, a routine sampling protocol was implemented because it was apparent that the Mysis had spread lake-wide. Samples were obtained on the new moon ( \pm the 3 least moon-lit

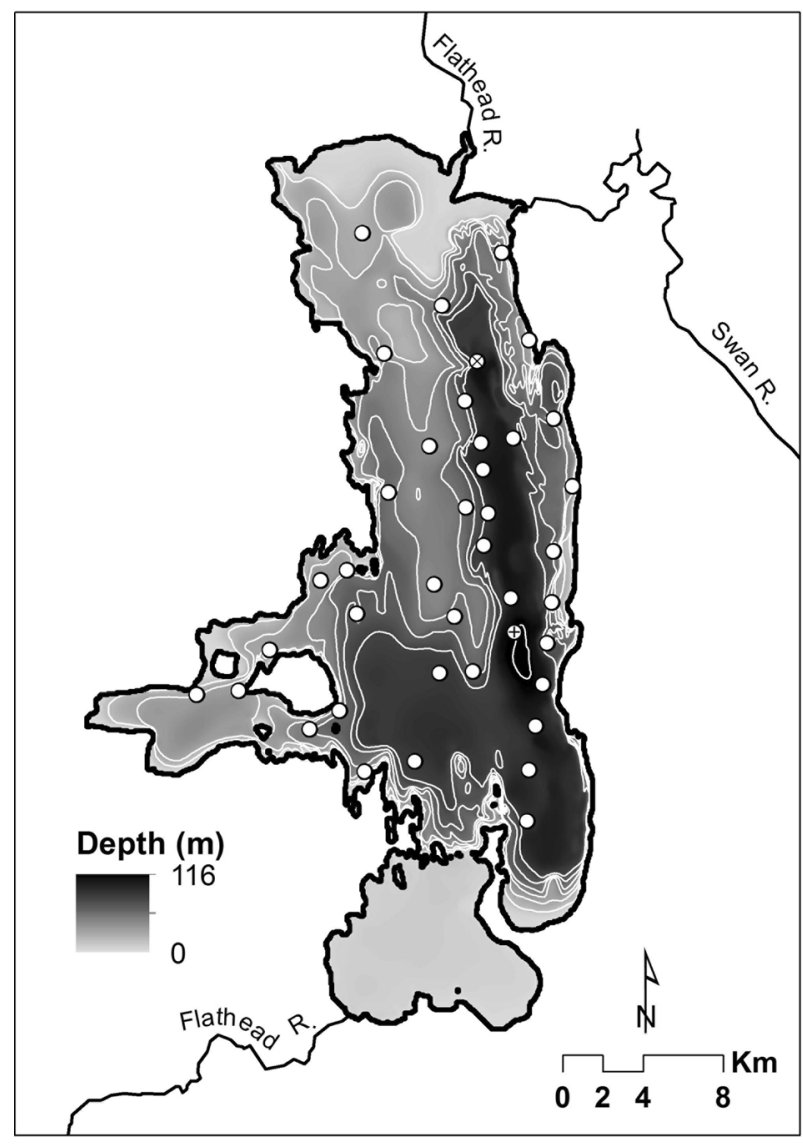

Figure 1. Sites for the annual census of the opossum shrimp, Mysis diluviana that invaded Flathead Lake, Montana (USA), in 1983. Site locations (open circles) are superimposed on the bathymetry of the lake, and filled to indicate MLD (+) and MLN ( $\times$ ) sampling sites. 
nights of the month) closest to September 1 of each year, beginning no earlier than one hour and forty minutes after sunset and ending one hour and forty minutes prior to sunrise. Samples obtained during late-season (late September-October) samplings ( $n=4$ years) were corrected for reduction in density as a result of mortality. Mortality was assessed by sampling several sites monthly from late summer through November and modeling the observed decline in Mysis abundance as a function of time. Sampling sites were spatially distributed across the lake and weighted in relation to the distribution of sampling depth intervals $(0-40 \mathrm{~m}, 40-75 \mathrm{~m}$, and $>75 \mathrm{~m}$ ) to calculate a whole-lake areal mean abundance. Additionally, we conducted monthly sampling from May to December in 1988 and in 1992-1993 at the MLD site (see Chess and Stanford 1998), and again in 2012-13 ( $n=4$ sites, including MLD-reported below), to study recruitment and life cycle variation. Throughout the period of record, samples were obtained with a closing net (diameter $=1 \mathrm{~m}$, net area $=0.79 \mathrm{~m}^{2}$, total length $=3.7-4.7 \mathrm{~m}$, mesh size $=0.5 \mathrm{~mm}$ ) hauled vertically from the lake bottom to the surface at $0.5 \mathrm{~m} \mathrm{~s}^{-1}$. Samples were immediately preserved in $95 \%$ ethanol. Mysid density $\left(\# \mathrm{~m}^{-2}\right.$ ) was calculated as the count of individuals divided by the area of the sampling net and net efficiency was considered to be 1 and consistent among tows.

We measured length of all individuals collected during monthly sampling in 1992-1993 and 20112014. Length was measured from the tip of the rostrum to the cleft of the telson to the nearest $0.1 \mathrm{~mm}$ using a dissection microscope with $10 \mathrm{X}$ oculars and 6 to 50X magnification. We identified sex and female reproductive class (for example, gravid, gravid-spent) for individuals greater than $8.0 \mathrm{~mm}$ in length. Individuals were identified as male in the presence of extended fourth pleopods, or as female in the presence of four thoracic plates or fully developed marsupium.

\section{Limnological Variables: Biological}

We quantified rates of primary production and structure of the planktonic community in Flathead Lake over the study period 1983-2014. In situ rates of primary production $\left(\mathrm{mg} \mathrm{C} \mathrm{m}^{-2} \mathrm{day}^{-1}\right)$ were estimated using incubation of radioactive ${ }^{14} \mathrm{CO}_{2}$ (as labeled bicarbonate) in a light-dark bottle experiment (Wetzel 2000) deployed across the vertical profile of the photic zone at MLD. Radiolabeled samples were analyzed by liquid scintillation counting. We collected integrated sample $(30 \mathrm{~m}$ to surface) with a tube and discrete (max fluores- cence) water samples at MLD for analysis of photosynthetic pigments (chlorophyll $a, \mathrm{CHL}$ ). CHL concentrations $\left(\mu \mathrm{gl}^{-1}\right)$ were determined using spectrophotometric analysis of pigments extracted in $90 \%$ acetone (Standard Methods 10200-H).

Phytoplankton were collected at MLD from integrated water samples that extended from $30 \mathrm{~m}$ in depth to the lake surface, and preserved in $1 \%$ Lugol's iodine solution. Taxa were identified to genus and enumerated using a Wild M40 compound microscope, first across an evenly distributed grid of 20 fields at $\times 140, \times 280$, and $\times 560$ magnification, and then an evenly distributed grid of approximately 70 fields at $84 \mathrm{X}$ magnification. Zooplankton were collected at MLD by vertical hauls using a mesh-paneled closing net (diameter $=0.3 \mathrm{~m}$, net area $=0.07 \mathrm{~m}^{2}$, total length $=$ $3.3 \mathrm{~m}$, mesh size $=64 \mu \mathrm{m}$ ) from $50 \mathrm{~m}$ to the lake surface $\left(0.4 \mathrm{~m} \mathrm{~s}^{-1}\right)$, and preserved in $4 \%$ formalin solution. Zooplankton taxa were identified to genus or species and enumerated using a LEICA DMLS compound microscope at $\times 40-\times 100$ magnification. We determined mean annual abundance of total phytoplankton (PHYT, $\# \mathrm{ml}^{-1}$ ) and zooplankton (ZOOP, $\# \mathrm{l}^{-1}$ ), and calculated the proportion of total ZOOP abundance represented by $D$. thorata (THOR; the primary prey resource of adult and subadult Mysis).

Data on relative abundance of fishes in Flathead Lake were assembled from annual reports of spring gill-net surveys executed by Montana Fish Wildlife and Parks and the Confederated Salish and Kootenai Tribes following protocols detailed in (Ellis and others 2011). Indices of lake trout (LKT) and Lake whitefish (LWF) relative abundance (reported as catch-per-unit-effort, CPUE) were summed across gill-net types (sinking and floating) to derive a single metric of relative abundance for the primary predators of Mysis.

\section{Limnological Variables: Chemical}

We measured nutrient ( $\mathrm{N}$ and $\mathrm{P}$ forms) concentrations at MLD and annual nutrient loading from the major tributaries of Flathead Lake. Whole-water samples were collected for the analysis of dissolved and total nutrients from integrated water samples (30 m to surface) at MLD, and grab samples from the thalweg of the two major tributaries, the Flathead and Swan Rivers that enter on the north shore. Dissolved nutrient samples were filtered to $0.45 \mu \mathrm{m}$. Filtered and whole-water samples were stored at $-20^{\circ} \mathrm{C}$. All forms of organic and inorganic nitrogen and phosphorus in whole-water samples were oxidized using alkaline persulfate 
digestion (USGS 03-4174). Colorimetric segmented flow analysis was used to determine the concentrations of ammonium-nitrogen $\left(\mathrm{NH}_{3}-\mathrm{N} ; \quad\right.$ EPA 350.1), nitrate+nitrite-nitrogen $\left(\mathrm{NO}_{3 / 2}-\mathrm{N} ; \quad\right.$ EPA 353.2), phosphate as soluble reactive phosphorus (SRP; EPA 365.2), total nitrogen (TN; EPA 353.2), and total phosphorus (TP; EPA 365.2).

\section{Limnological Variables: Physical}

We measured temperature $\left({ }^{\circ} \mathrm{C}\right)$ and photosynthetically active radiation (PAR; $\mu \mathrm{E} \mathrm{m}^{-2} \mathrm{~s}^{-1}$ ) across the depth profile at MLD 12-17 times per year. Instruments were Hydrolab DS5 multi-probe sensor (Hach Environmental, Loveland, CO, USA) and LI-193 spherical quantum sensor (Li-Cor, Inc., Lincoln, NE, USA), respectively. We calculated depth to $1 \%$ incident light in order to determine the extent of the photic zone and calculated relative thermal resistance to mixing (RTRM) as an index of stratification from depth-temperature profiles and determined the position of the thermocline (maximum RTRM) and thickness of the metalimnion (minimum and maximum depth $\geq 20$ RTRM) (Vallentyne 1957) on all sampling dates. Depth from surface to top of metalimnion was used to calculate epilimnetic volume $\left(\mathrm{km}^{3}\right)$ using a depth to lake volume relationship $\left(\mathrm{km}^{3}=\right.$ $-0.00225 x^{2}+0.44452 x, \quad r^{2}=0.999, \quad x=$ depth). Lake volume was calculated at six-meter increments from depth-temperature and bathymetric profiles and multiplied by temperature and the specific heat of water $\left(\mathrm{J} \mathrm{kg}^{-1} \mathrm{~K}^{-1}\right)$ to calculate internal energy in Joules (IE) as a measure of thermal mass of the water column at MLD (v1.7.6 of r-LakeAnalyzer: Package for the Analysis of Lake Physics, Winslow and others 2015). We calculated the proportion of the photic zone that is $<15^{\circ} \mathrm{C}$ as an index of mysid accessibility based on thermal tolerance (Beeton 1960; Gal and others 2004).

Annual means of El Nino Southern Oscillation (ENSO) and Pacific Decadal Oscillation (PDO) climate indices were calculated from monthly means obtained from http://www.esrl.noaa.gov/psd/enso/ mei/index.html. Whited and others (2007) showed that the climate (temperature, precipitation, and runoff) of the Flathead Basin is strongly coherent with these indices.

We calculated mean annual discharge $\left(\mathrm{Q} ; \mathrm{l} \mathrm{s}^{-1}\right)$ from daily discharge measurements for the major tributaries of Flathead Lake obtained from the USGS National Water Information System (http:// waterdata.usgs.gov/nwis/). We determined that on average, $5 \%$ of the total discharge of the main stem of the Flathead River was contributed by minor tributaries below the confluence of the major tributaries (South, Middle, and North Forks of the Flathead), and therefore we utilized continuous daily discharge data from the gaging station immediately below the confluence of the major tributaries in order to minimize gaps in data collection.

\section{Spatial Distribution of Mysis}

We modeled the distribution of Mysis in Flathead Lake over time using inverse distance-weighted deterministic spatial interpolation (100-m resolution) in ArcGIS Spatial Analyst (ArcGIS Desktop: Release 10.3, Environmental Systems Research Institute, Redlands, CA, USA). Interpolated lake-wide distributions of Mysis were based on sitespecific densities from 1987 (to represent distribution during invasion) and mean site-specific densities each year from 1991-2014. Densities were then treated as features for input into spatial clustering analysis in order to investigate intraannual distribution of Mysis in the lake (see "Data Analysis" section below).

\section{Data Analysis}

Annual means for biological, chemical, and physical variables collected over the study period of 1983-2014 were calculated by water year (October 1-September 30). Annual means for discrete measurements and samples collected at irregular intervals were calculated from monthly means to detrend and prevent unequal weighting by season, except for discrete measures of primary production which were interpolated to calculate mean annual rates (PPR expressed as $\mathrm{g} \mathrm{C} \mathrm{m}^{-2} \mathrm{y}^{-1}$ ) and annual rates of nutrient loading from tributaries which were calculated by numeric integration of daily rates. In general, 15 sampling events took place each year for all variables. Within a year, the frequency of sampling ranged from every 2 weeks while the lake was stratified and to every 46 weeks while the lake was mixed.

We conducted bivariate Pearson correlations for exploratory analysis of relationships between limnological variables and mean annual lake-wide abundance over the period of record (1983-2014), and within three discrete periods of time identified based on distinct patterns in abundance and lakewide variability (1983-1993, 1994-2004, 20052014), because we expected that we would saturate the regression if we fully parameterized the model. No consistent relationships were found via direct one-on-one comparisons. Thus, we employed a linear stepwise multiple regression (bidirectional) analysis to test for combined effects of limnological 
(independent) variables (Table 1) on annual mysid abundance over the years 1983-2014. To prevent saturation of multiple regression models (\# variables $>$ \# observations), we categorized variables as biological, chemical, or physical and initially tested three independent models: (1) biological (BIO), (2) chemical (CHEM), and (3) physical (PHYS). Variables included in the BIO model were also lagged by one year to evaluate the degree to which the structure of the food web in the previous year predicted annual abundance of Mysis in the following year. Mean annual mysid abundance in the previous year $\left(M Y S_{t-1}\right)$ was included in this laggedregressor assessment. Variables composing the independent models were determined using the Akaike Information Criterion (AIC), and included in a merged model (BIO + CHEM + PHYS) to determine the extent to which variables predicted mean annual lake-wide density of Mysis. We calculated the relative importance of predictor variables included in final stepwise multiple regression models as an index of relative contribution of a variable to total predictable variance by itself and in combination with other predictor variables (sensu Johnson and Lebreton 2004). We investigated the error distributions associated with each predictor variable and found error to be normally distributed; thus, we did not use any transformations throughout the regression analysis.

We analyzed intraannual clustering of high- and low-density Mysis using local indicators of spatial association (Getis-Ord Gi* method; Getis and Ord 1992) among site-specific densities in Flathead Lake. This test assesses autocorrelation within a "neighborhood" of locations within a defined dis- tance and identifies areas of density relatedness and significant clustering at the distance-specific scale (that is, "hot- and cold-spots"). We used Euclidian distance and fixed-distance-band methods in the clustering analysis. Z-scores were generated for each feature point, which, if less than -1.96 or greater than 1.96 are considered significant at alpha $=0.05$. The magnitude of the Z-score indicates intensity of clustering, where positive $\mathrm{Z}$ values with associated $p<0.05$ are considered "hot spots," and negative $\mathrm{Z}$ values with associated $p<0.1$ are considered "cold spots" of density.

Mysids collected from intermittent monthly samples at MLD in 1992-1993 and 2012-2013 were classified into cohorts based on size-frequency analysis. Annual growth rates for young-of-year (YOY) cohorts were calculated as the slope of modal length over time $\left(\mathrm{mm}\right.$ month $\left.^{-1}\right)$. We pooled counts of Mysis across replicated hauls within year for a particular month, and used a one-way analysis of variance (ANOVA) and post hoc pairwise t-tests with Bonferroni-adjusted p-values to test for differences among mean abundance of juveniles in the fall (August - November) across years 1992-1993 and 2012-2013. All statistical analyses were performed using R Statistical Software (v 3.2.0, R Foundation for Statistical Computing, Vienna, Austria).

\section{RESUlts \\ Long-Term Temporal Dynamics and Potential Drivers}

We identified three periods of Mysis establishment and proliferation in the 33-year Flathead Lake da-

Table 1. Results of Stepwise Multiple Regression Analysis (Bidirectional) of Biological, Chemical, and Physical Factors on Annual Densities of M. diluviana in Flathead Lake (MT, USA) Over Years 1985-2014

\begin{tabular}{|c|c|c|c|c|c|c|c|c|c|c|}
\hline Linear model & Variable & $\beta$ & SE & $t$ & $p>t$ & $R I^{1}$ & $F$ & $p>F$ & $R^{2}$ & $R_{\mathrm{a}}^{2}$ \\
\hline \multirow[t]{5}{*}{ Biological (BIO) } & MYS $_{t-1}$ & 0.74 & 0.16 & 4.605 & 0.0002 & 0.42 & \multirow[t]{5}{*}{8.116} & \multirow[t]{5}{*}{0.0003} & \multirow[t]{5}{*}{0.67} & \multirow[t]{5}{*}{0.59} \\
\hline & THOR & -856.96 & 310.34 & -2.761 & 0.0120 & 0.25 & & & & \\
\hline & $\mathrm{CHL}_{0-30 \mathrm{~m}}$ & -90.55 & 38.23 & -2.369 & 0.0280 & 0.07 & & & & \\
\hline & $\mathrm{CHL}_{\text {MAX }}$ & 49.16 & 29.75 & 1.653 & 0.1140 & 0.03 & & & & \\
\hline & PPR & -1.52 & -0.38 & -4.028 & 0.0007 & 0.23 & & & & \\
\hline \multirow[t]{2}{*}{ Chemical (CHEM) } & $\mathrm{TN}_{\text {LAKE }}$ & 0.82 & 0.28 & 2.927 & 0.0081 & 0.40 & \multirow[t]{2}{*}{9.527} & \multirow[t]{2}{*}{0.0011} & \multirow[t]{2}{*}{0.48} & \multirow[t]{2}{*}{0.43} \\
\hline & $\mathrm{TP}_{\text {LAKE }}$ & -16.92 & 4.79 & -3.53 & 0.0020 & 0.60 & & & & \\
\hline Physical (PHYS) & EPIV & -10.53 & 3.49 & -3.020 & 0.0063 & 1 & 9.123 & 0.0063 & 0.29 & 0.26 \\
\hline \multirow[t]{5}{*}{$\mathrm{BIO}+\mathrm{CHEM}+\mathrm{PHYS}$} & MYS $_{t-1}$ & -0.25 & 0.13 & 1.878 & 0.0766 & 0.14 & \multirow[t]{5}{*}{5.868} & \multirow[t]{5}{*}{0.0022} & \multirow[t]{5}{*}{0.62} & \multirow[t]{5}{*}{0.51} \\
\hline & THOR & -324.67 & 245.10 & -1.325 & 0.2019 & 0.18 & & & & \\
\hline & $\mathrm{TN}_{\text {LAKE }}$ & 0.70 & 0.2524 & 2.785 & 0.0122 & 0.28 & & & & \\
\hline & $\mathrm{TP}_{\text {LAKE }}$ & -13.03 & 5.52 & -2.360 & 0.0298 & 0.16 & & & & \\
\hline & EPIV & -7.06 & 2.94 & -2.401 & 0.0274 & 0.24 & & & & \\
\hline
\end{tabular}

${ }^{I}$ Relative importance (RI): an index of relative contribution of a variable to total predictable variance by itself and in combination with other predictor variables (sensu Johnson and Lebreton 2004). 
taset, based on variability in abundance: (1) Invasion (1983-1993), characterized by exponential increase to peak density and subsequent decline, (2) Stabilization (1994-2004), characterized by low variability and an increase to a second peak and subsequent decline, and (3) Oscillation (2005 2014), characterized by high-magnitude interannual fluctuation (Figure 2). To examine relationships between potential drivers of annual abundance of Mysis, we produced three models, one each for biological (BIO), chemical (CHEM), and physical (PHYS) variables. We initially considered all 25 independent variables described above (see Supplementary Materials), but we eliminated phytoplankton community composition (PHYT) and fish abundance $\left(\mathrm{FISH}_{\mathrm{CPUE}}\right)$ from the analysis due to the limited number of observations, and internal energy (IE) was removed due to autocorrelation with temperature. The BIO model showed that 5 of the 7 biological variables were important predictors of mean annual abundance of Mysis: previous year mysid abundance $\left(\mathrm{MYS}_{\mathrm{t}-1}\right)$, proportion of $D$. thorata (THOR), integrated chlorophyll $a$ concentration $\left(\mathrm{CHL}_{0-30 \mathrm{~m}}\right)$, maximum chlorophyll $\left(\mathrm{CHL}_{\mathrm{MAX}}\right)$ and primary production (PPR) (Table 1). Together, these five biological variables encompassed over half of the variability observed in annual lake-wide mysid abundance $\left(n=26, R_{\mathrm{a}}^{2}=0.59, p=0.0003\right)$. Of the explanatory

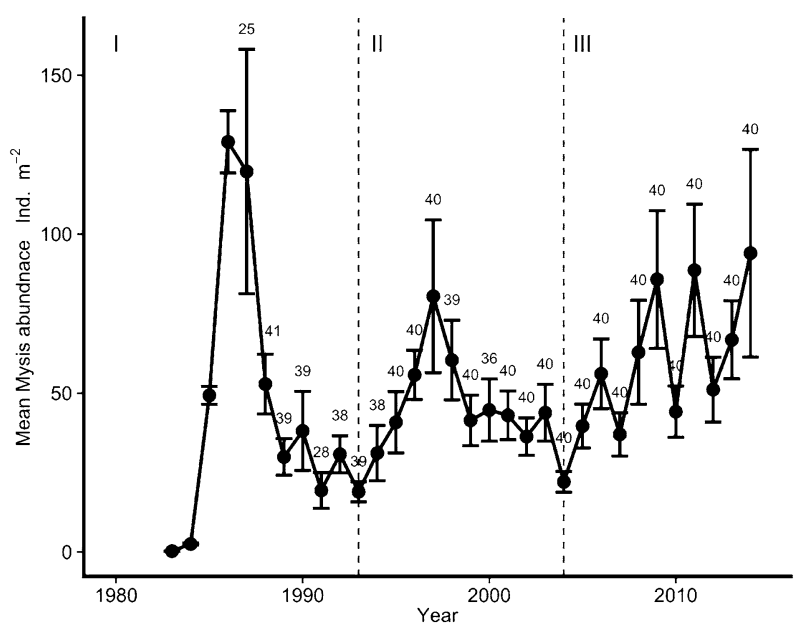

Figure 2. Annual mean abundance of $M$. diluviana in Flathead Lake. Data are weighted by the proportion of relative depth of the collection sites. Error bars represent 95\% confidence limits. Over the 30 year dataset, there are three distinct periods: $(I)$ an exponential growth period (invasion) followed by a period of decline, (II) stabilization with little variation between years and (III) an oscillation period with high variation between sites and years and an increasing trend in abundance. Labels above symbols indicate the number of sites sampled annually power provided by the BIO model $(\sim 60 \%$ of total variation), the relative contribution to the explanatory power varied across predictors: $\mathrm{MYS}_{t-1}$ $(42 \%)$, THOR $(25 \%)$, and PPR $(23 \%)$, CHL $(10 \%)$. MYS $_{t-1} \quad(\beta=0.74, \quad p=0.0002), \quad$ and $\mathrm{CHL}_{\mathrm{MAX}}$ $(\beta=49.16, p=0.1140)$ were positively correlated, while THOR $(\beta=-856.96, p=0.0120), \mathrm{CHL}_{0-30 \mathrm{~m}}$ $(\beta=-90.55, p=0.0280)$, and PPR $(\beta=-1.52, p=$ $0.0007)$ were negatively correlated to Mysis abundance (Table 1).

The stepwise multiple regression on chemical variables (CHEM) identified significant relationships between annual mysid abundance and water column total nitrogen $\left(\mathrm{TN}_{\mathrm{LAKE}}\right)$ and total phosphorus $\left(\mathrm{TP}_{\text {LAKE }}\right) ; \operatorname{TN}_{\mathrm{LAKE}}(\beta=0.82, p=0.0081)$ was positively correlated and $\operatorname{TP}_{\mathrm{LAKE}}(\beta=-16.92$, $p=0.0020$ ) was negatively correlated (Table 1). Overall, the CHEM model was associated with nearly half of the variability in annual abundance $\left(n=24, R_{\mathrm{a}}^{2}=0.43, p=0.0011\right)$.

The physical regression (PHYS) identified a strong relationship between mysid abundance and epilimnetic volume (EPIV), which together related approximately one-third of the variability observed in annual lake-wide abundance $\left(n=24, R_{\mathrm{a}}^{2}=0\right.$. $26, p=0.0063)$. EPIV $(\beta=-10.53, p=0.0063)$ was negatively related to Mysis abundance (Table 1).

When limnological variables from each independent model were combined into a single predictive model (BIO + CHEM + PHYS), MYS $_{t-1}$, THOR, $\mathrm{TN}_{\mathrm{LAKE}}, \mathrm{TP}_{\mathrm{LAKE}}$, and EPIV were the significant predictors of mean annual abundance over the years 1988-2011 (Table 1). Together, these five variables were associated with over half of the variability observed in annual lake-wide abundance $\left(n=24, R_{\mathrm{a}}^{2}=0.51, p=0.0022\right)$. The total explanatory power in the model was distributed among THOR $(18 \%), \operatorname{TN}_{\text {LAKE }}(28 \%), \quad$ TP $_{\text {LAKE }}$ $(16 \%)$, EPIV $(24 \%)$, and MYS $_{t-1}(14 \%)$. In this biophysical model, $\operatorname{TN}_{\text {LAKE }}(\beta=0.70, p=0.0122)$ was positively correlated and $\mathrm{MYS}_{t-1}(\beta=-0.25$, $p=0.0766)$, THOR $(\beta=-324.67, \quad p=0.2019)$, $\operatorname{TP}_{\text {LAKE }}(\beta=-13.03, p=0.0298)$, and EPIV $(\beta=$ $-7.06, p=0.0274)$ were negatively correlated with Mysis abundance (Table 1). When nonmortalitycorrected lake-wide annual mysid densities were included in the stepwise multiple regression, the significance of the THOR variable increased $(p=$ 0.2019 to 0.0699 ), suggesting a robust relationship between THOR and annual mysid density, regardless of the a posteriori mortality adjustments.

Owing to reduced numbers of observations that caused saturation in the regression approach when the long-term abundance record was parsed into 
invasion (1983-1993), stabilization (1994-2004), and oscillation (2005-2014) periods, we calculated bivariate Pearson $r$ correlations for each of the limnological variables in relation to mean annual mysid abundance within periods. During invasion (1983-1993), THOR $(r=-0.72, t=-2.731, \mathrm{df}=7$, $p=0.0293)$ and EPIV $(r=-0.72, \quad t=-2.737$, $\mathrm{df}=7, \quad p=0.0291)$ were negatively related to mean annual abundance, whereas $\mathrm{MYS}_{t-1}$, $(r=0.58, t=2.034$, $\mathrm{df}=8, p=0.0801)$ was positively related, but slightly exceeded $\alpha=0.05$. During stabilization (1994-2004), ZOOP $(r=-0.64$, $t=-2.5214, \mathrm{df}=9, p=0.0327)$ and $\mathrm{NO}_{2 / 3}-\mathrm{N}_{\mathrm{LAKE}}$ $(r=0.63, t=2.4036, \mathrm{df}=9, p=0.0397)$ were significantly related to mean annual mysid abundance. During the oscillation period (2005-2014), $\mathrm{TP}_{\text {LAKE }}(r=-0.73, t=-3.042, \mathrm{df}=8, p=0.0160)$ and EPIV $(r=-0.56, \quad t=-1.9036, \quad \mathrm{df}=8$, $p=0.0935)$ were negatively correlated with mean annual abundance of Mysis, but EPIV also slightly exceeded $\alpha=0.05$.

\section{Spatial Distribution}

The periods of invasion, stabilization, and oscillation were also characterized by distinct spatial density distributions (Figure 3). During the invasion peak (1987), the range in site-specific densities varied by two orders of magnitude (0-552 Mysis $\left.\mathrm{m}^{-2}\right)$ and high density sites ("hot spots") were strongly clustered near the deep trench center of the lake (Figure 3). Within 6 years (1991), Mysis decreased dramatically becoming less abundant and more dispersed throughout the lake. Maximum sitespecific density observed during this year did not exceed 100 Mysis $\mathrm{m}^{-2}$. A "cold spot" (that is, cluster of low-density sites) was observed at the shallow north end of the lake near the mouth of the major inlet tributaries, while a weak but relative "hot spot" was observed at sites distributed along the deep-water trench.

Although all three periods were characterized by intersite variability associated with depth, the highest interannual variability in site-specific densities throughout the lake occurred during the more recent oscillation period (Figure 2). Throughout the period of record, mean annual abundance was approximately $60 \%$ lower on average at sites less than $40 \mathrm{~m}$ in depth than at $75 \mathrm{~m}$ or greater in depth. Mean annual density ranged from $8.6 \mathrm{~m}^{-2}$ in 1991 to $89.8 \mathrm{~m}^{-2}$ in 2014 at sites less than $40 \mathrm{~m}$, from $20.3 \mathrm{~m}^{-2}$ in 1991 to $167.9 \mathrm{~m}^{-2}$ in 1987 at sites $40-75 \mathrm{~m}$ in depth, and from $32.4 \mathrm{~m}^{-2}$ in 2004 to $23 \mathrm{~m}^{-2}$ in 1987 at sites greater than $75 \mathrm{~m}$ in depth. Mean annual abundance at shallow sites exceeded those at sites greater than $40 \mathrm{~m}$ only five times (2000, 2001, 2003, 2005, and 2014) over the 28-year record (1987-2014). However, densities observed at shallow sites have substantially increased over time since invasion.

\section{Life History Variability}

Relative abundance of Mysis size classes varied by month (August-November) across years (19921993, 2012-2013; Figure 4). We identified two to three distinct cohorts within years: (1) Pl, comprised remnant adults from the breeding population of the previous year, (2) Fl, comprised YOY recruits that formed the active breeding population, and (3) F2, comprised offspring produced by F1 within the same year. We observed bimodal distributions of length in August across all years, indicating the presence of Pl and F1. By September, distributions appeared marginally unimodal (except for slight bimodality in 2013) indicating mortality of Pl and eclipse by Fl as they grow and reach maturity. Clear bimodality was again present in October and November for years 2012 and 2013, suggesting the release of $\mathrm{F} 2$ by individuals of $\mathrm{F} 1$ that reached maturity earlier in the season (Figure 4).

The relative proportion of juvenile $(<12 \mathrm{~mm})$ Mysis at MLD in the fall varied across years 19921993 and 2012-2013 (Figure 5). In August, we observed similarly high densities of juveniles for 1992 and 2013, with the lowest abundance of juveniles occurring in 1993, and similarly low densities of juveniles in 2012, but differences among years were not significant $(p=0.158)$. Limited replication in 2012 and 2013 prevented statistical assessment of abundance of juveniles in September, but 1992 and 1993 were similar and intermediate to the low abundance in 2012 and high abundance in 2013. In October, mean abundance of juveniles in 2012 and 2013 was nearly ten to thirty times greater than that observed in 1992 and $1993(p<0.0001)$. In November, significantly greater densities of juvenile Mysis were observed in 2012 and $2013(p=0.0226)$. It should be noted that juvenile Mysis appeared at very low abundance during these late fall surveys.

\section{Discussion}

The abundance of Mysis has varied greatly over the past three decades in Flathead Lake and our analysis demonstrates that bottom-up regulation mediated through physical, chemical, and biological factors are related to the observed fluctuations 


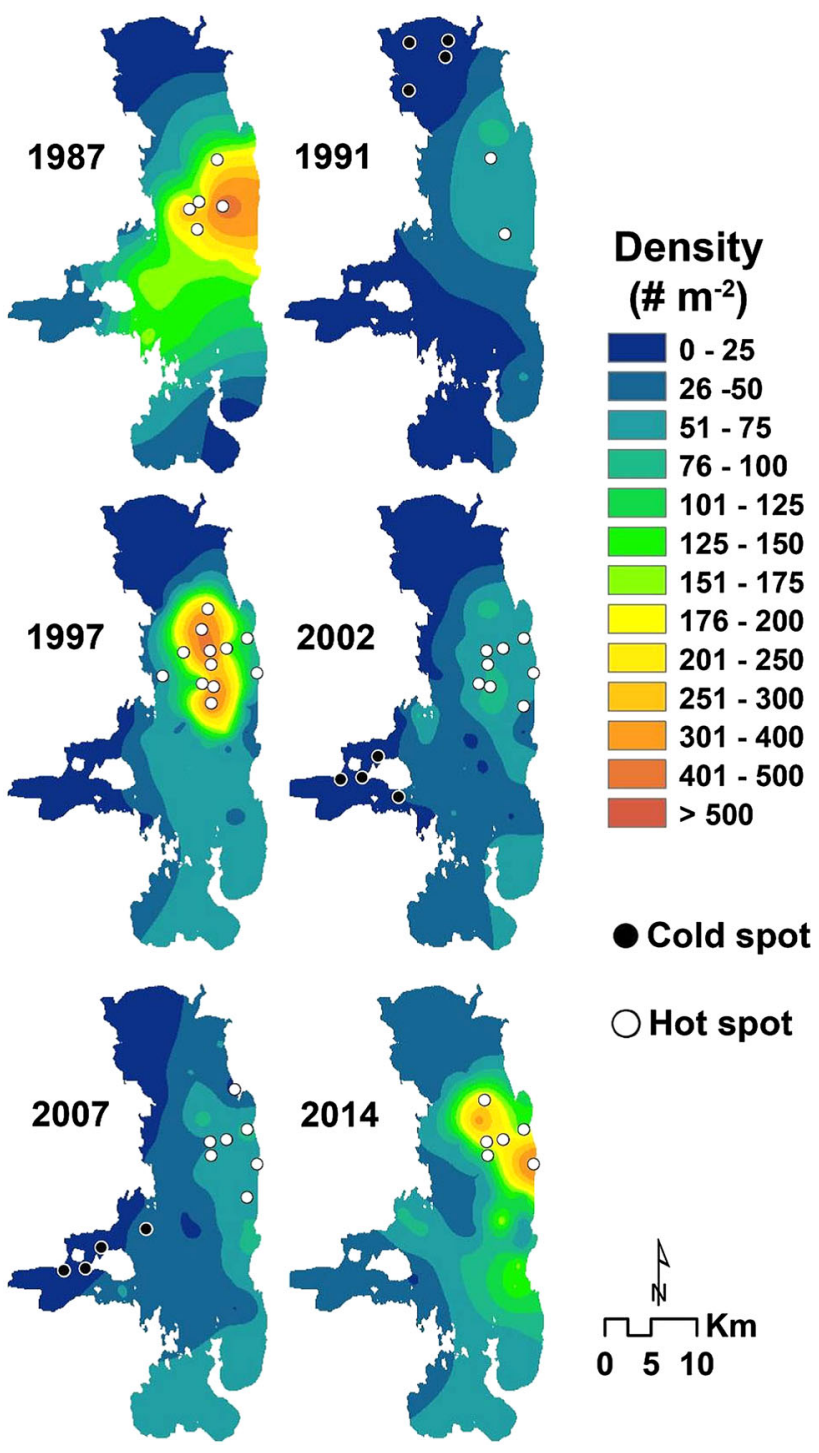

in mysid density over time as shown conceptually in Figure 6. However, the orientation of the relationships (positive or negative correlations) between the biological and chemical variables indicate that the Mysis are strong interactors in the food web and are likely regulating the temporal variability of bottom-up factors, rather than the mysid population being regulated. Spatial distribution of Mysis within Flathead Lake has varied over time, since its invasion and is characterized by periodic hot- and cold-spots of abundance and increasing use of shallow zones over the period of record (1981-2014). We found strong evidence of plasticity in the life cycle of Mysis, and suggest that this plasticity relates to spatial and temporal dynamics in key environmental factors and food web structure. We suggest that this flexibility may also be a response to changing resource availability that is coupled with behaviorally mediated release
Figure 3. Spatial distribution of mysid densities (abundances) in Flathead Lake. The color gradient represents the range of site-specific abundances observed in each year. Open circles indicate areas of high abundance ("hotspots") and closed circles are areas of low abundance ("cold spots"). Each pair of graphics is composed of the low and high density years for each of the three periods shown in Figure 2. of top-down control (predator avoidance by DVM), which enables Mysis to act as a dynamic interactor in the Flathead Lake food web.

Our first-order analysis investigated biophysical variables (BIO, CHEM, and PHYS) in Flathead Lake mysid dynamics in order to determine which variables to include in a combined model. When biological factors were considered independent of physical and chemical conditions, mean annual mysid abundance was negatively related to PPR, $\mathrm{CHL}_{0-30 \mathrm{~m}}$, and abundance of their primary prey species, $D$. thorata, suggesting effective and thorough exploitation of resources at lower trophic levels. This supports our observation that years with abundant resources were coherent with low Mysis abundance and vice versa, demonstrating that $M y$ sis are driving lower numbers of basal resources and are not limited by food availability. Moreover, previous studies have demonstrated that the mysid 


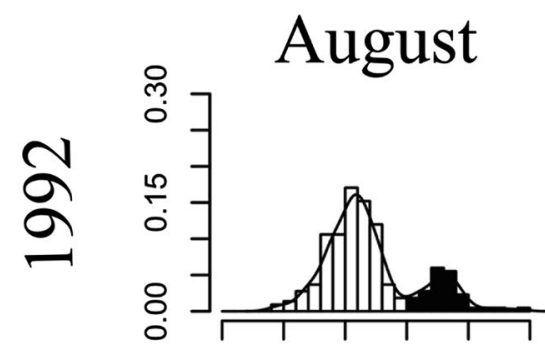

September

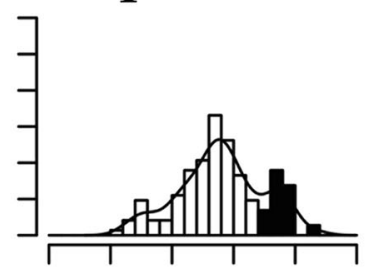

October
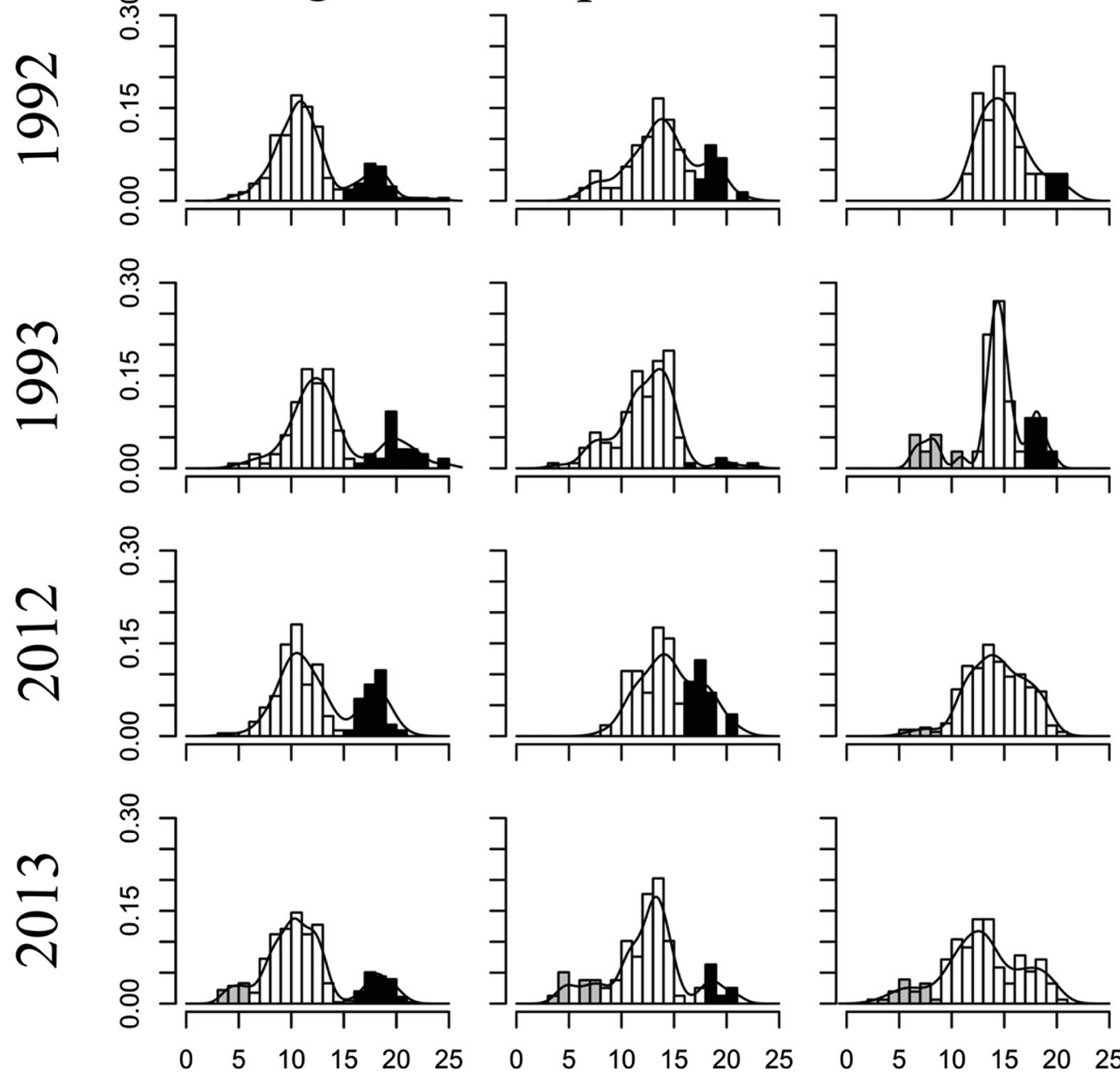
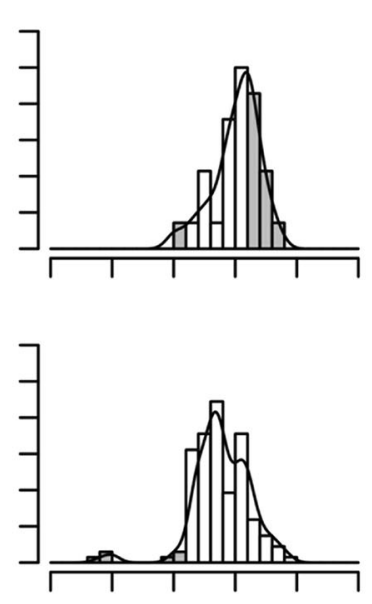

November
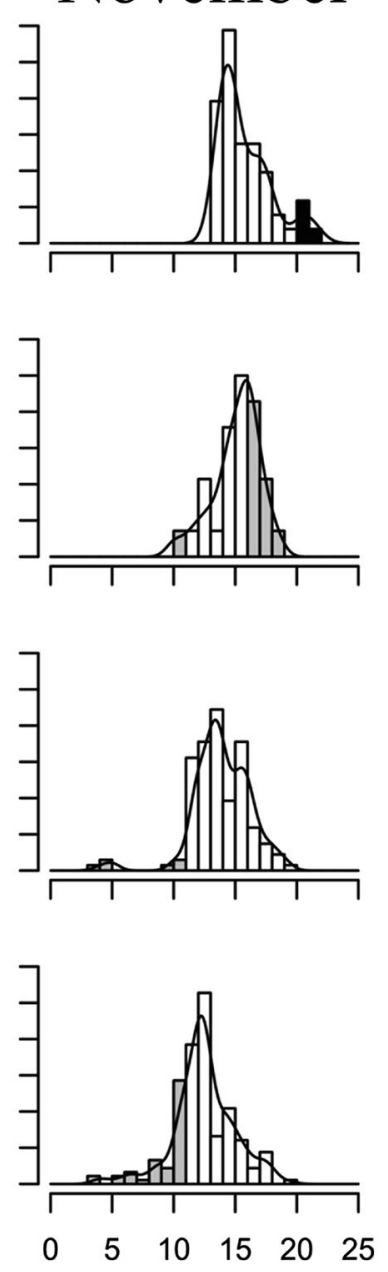

Figure 4. Size-frequency distributions of mysids in Flathead Lake during August through November. Data are presented for periods 1993-1994 and 2012-2013. Black filled bars represent the parental generation, white represents juveniles, and gray represents neonates. During the most recent period (2012-2013), when densities were highly variable between years and sites, there is a distinct life history shift toward multiple broods per year.

invasion of Flathead Lake induced a shift in the structure of the zooplankton community from larger to smaller forms, with the exception of largebodied $D$. thorata which now dominate cladoceran numbers (Ellis and others 2011; Spencer and others 1999). Preferential feeding on $D$. thorata during years where this prey species is abundant may induce enhanced grazing on phytoplankton by nowabundant small size classes of zooplankton (Ellis and others 2011). This interaction in combination with grazing on phytoplankton by omnivorous juvenile Mysis may drive the negative relationship detected between mysid abundance and $\mathrm{CHL}_{0-30 \mathrm{~m}}$ and PPR. Thus, we believe that the mysid population functions as a top-down regulator of lower trophic levels over the long term (that is, Figure 6).
Indeed, the nonsignificant but substantial positive trend between mean annual abundance and $\mathrm{CHL}_{\text {MAX }}$ indicates that mysid zooplanktivory is focused within the upper metalimnion leading to a spike in algal biomass. During stratification, temperatures of epilimnetic waters are above $15^{\circ} \mathrm{C}$ and owing to their strong preference for cold water, Mysis do not habitually penetrate the thermocline. Mysid predation on zooplankton likely is intense in the metalimnion and virtually absent in the epilimnion, allowing the $D$. thorata population to maximize abundance during stratification, as we have observed annually. Epilimnetic grazing of phytoplankton by the expanding zooplankton population likely drives the observed negative relationship with $\mathrm{CHL}_{0-30 \mathrm{~m}}$ and positive relation- 


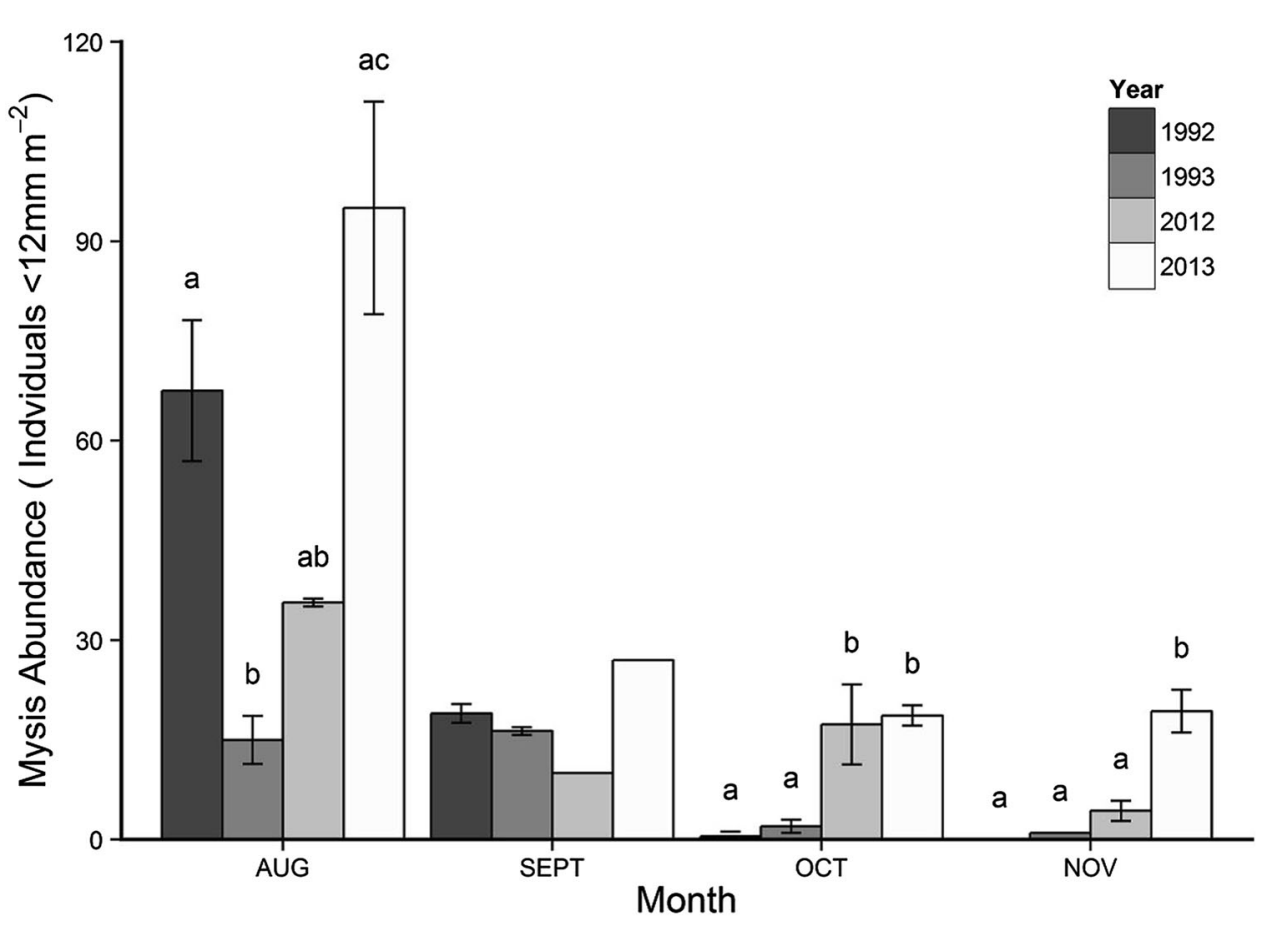

Figure 5. The abundance of juvenile mysids observed monthly in 1992-1993 and 20122013. Note that significantly more juveniles occurred in recent years compared to 1992-1993, also indicating a change in life cycle.

ship with $\mathrm{CHL}_{\mathrm{MAX}}$. Zooplankton grazing by Mysis has been shown in other lakes to concentrate at the metalimnion (Bowers and Grossnickle 1978). Mysis can also act as an omnivorous component of the food web that utilizes multiple trophic levels depending on resource abundance and stage of development ( $\mathrm{O}^{\prime}$ malley and others 2014), and in Flathead Lake, Mysis likely have a direct role in regulating PPR to a small degree as indicated by the significant negative relationship with PPR. However, ultimately the indirect trophic interactions mediated through zooplankton predation by the Mysis are much more apparent. Mysids will heavily graze zooplankton when available including agile copepods; however, in Flathead Lake, their main zooplankton prey are slower-moving Daphnia that are not adapted to evade mysid predation (Chess and Stanford 1998).

The extent to which limnological variables interact with abundance of Mysis is related to how these factors organize the structure and function of the Flathead Lake food web. Nutrient availability and light drive primary productivity in all lakes (Wetzel 2000), and thus the energy available to consumers. Spencer and Ellis (1998) demonstrated that colimitation of nitrogen and phosphorus controlled phytoplankton biomass in Flathead Lake, however, inverse trends in loading of nitrogen and phosphorus to Flathead Lake were observed over the period of record through 2005 and continue today (Ellis and others 2011, 2015). The increased nitrogen loading and deposition comes from dust, smoke, especially from forest and range fires, within and beyond the Flathead catchment. Increased nitrogen loading likely has increased phosphorus limitation of primary production. We observed a negative relationship between mean annual abundance of Mysis and TP and a positive relationship between mysid abundance and TN. Thus, the general increase in mysid numbers though time is coherent with the increase in water column TN and increased nitrogen deposition. The negative relationship with TP appears to be more linked to trophic interactions and sedimentation of ungrazed phytoplankton into the metalimnion. When mysid abundance is low, TP, D. thorata abundance, PPR, and $\mathrm{CHL}_{0-30 \mathrm{~m}}$ are correspondingly high, whereas the $\mathrm{CHL}_{\text {MAX }}$ remains low. In low TP periods, abundant zooplankton graze phytoplankton causing faster cycling of organic to inorganic forms of $\mathrm{P}$ within the epilimnion, which then increases PPR, allowing high $\mathrm{CHL}_{0-30 \mathrm{~m}}$ (Elser and Goldman 1991). A positive feedback allows for more phytoplankton for zooplankton to graze, fueling increased PPR with higher TP. Higher grazing rates lead to less potential sedimentation to the metalimnion. $\mathrm{CHL}_{\mathrm{MAX}}$ is reduced explaining the positive relationship observed between Mysis and $\mathrm{CHL}_{\text {MAX. }}$. When Mysis are abundant, the opposite takes place and more phytoplankton settle into the metalimnion, thereby increasing the $\mathrm{CHL}_{\text {MAX }}$. Further, not only is epilimnetic cycling of $P$ reduced when Mysis have lowered D. thorata abundance, but more TP also stays entrained in 


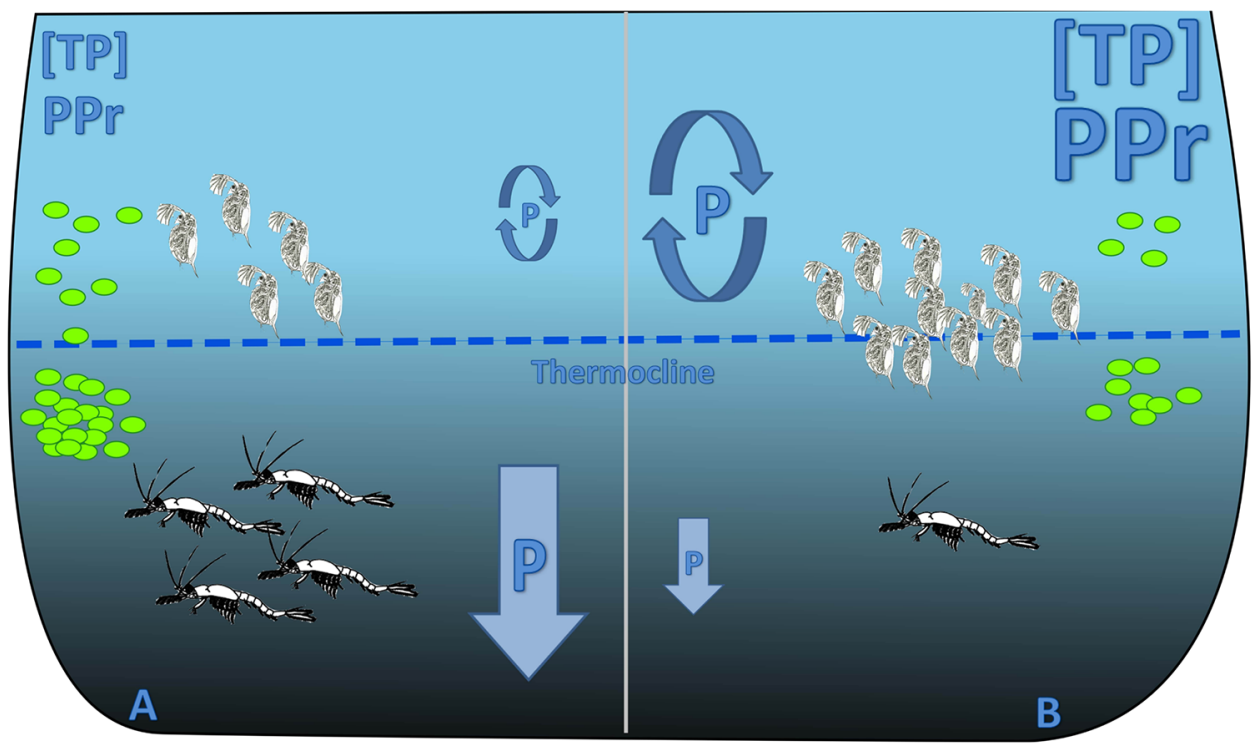

Figure 6. A conceptual diagram of the interactions between Mysis and the biochemical properties of the food web in Flathead Lake. When Mysis are abundant $(\mathbf{A})$ there are correspondingly low numbers of Daphnia, which in turn reduces algal grazing leading to increased settling rates of algae and higher concentrations of Chl a in the deep chlorophyll maxima (DCM). This leads to a reduction of total $\mathrm{P}$ and recycling of $\mathrm{P}$ in the epilimnion which reduces primary production. Further, with increased biomass in the DCM, the potential for P settling into the hypolimnion is high. When Mysis is in low abundance (B), Daphnia numbers are high which keeps algal biomass low. High grazing rates leads to less algae settling into the DCM and increases TP and P recycling in the epilimnion. This reduces the potential for P to settle out of the photic zone which in turn stimulates primary production.

phytoplankton tissue and leaves the epilimnion via sedimentation. These interactions are shown in Figure 6 and explicitly underscore how the Mysis function as strong interactors, thereby regulating and structuring the food web in Flathead Lake as well as strongly influencing nutrient cycling.

We observed a negative relationship between mean annual abundance of Mysis and epilimnetic volume, an observation consistent with physiological thermal restrictions that inhibit Mysis from entering the warmer waters of the epilimnion. Presumably, during years in which volume of the epilimnion is relatively large, a greater proportion of the water column is inaccessible to Mysis (much of which is within the photic zone) but readily accessible by their prey, and thereby mysid access to food resources is restricted for at least a portion of the growing season.

When considered together, the relationships observed between the environmental variables and abundance of Mysis reflect organization of the chemo-physical template on which the food web is structured, and within which Mysis act as a dynamic interactor. In Flathead Lake, Mysis has functionally replaced kokanee salmon and cutthroat trout as the dominant zooplanktivore (Ellis and others 2011), which is indicated in our study by the strongly negative relationship between Mysis and D. thorata. When abundant, Mysis regulate TP concentration by increasing metalimnetic phytoplankton biomass and phosphorus uptake which then may settle out of the photic zone, whereas mysid numbers have increased as TN loading has increased over the 33-year period of record. It is unclear if nutrient recycling by Mysis via excretion could contribute to the observed increases in $\mathrm{TN}$ and requires further research. When the loss of thermal habitat induced in the surface layers of the lake by the deepening of the thermocline is considered, the relationship between TP and D. thorata in particular becomes more relevant. Increased epilimnetic volume that is too warm for Mysis to penetrate allows $D$ thorata to increase dramatically, which in turn, graze phytoplankton and increase turnover efficiency of phosphorus and reduce CHL (Ellis and others 2011). Hence, a very transparent epilimnion occurs during stratification every summer in Flathead Lake. Lastly, Mysis abundance in the previous year has a large role in determining the ability of Mysis to remain abundant; however, this phenomenon is puzzling considering the vast swings in abundance within the oscillation period. 
Our observation that in recent years Mysis are more abundant in shallow zones of Flathead Lake also requires linked multivariate consideration. Juvenile Mysis are more tolerant of higher light and temperature conditions (Boscarino and others 2010) and the recent increase in late fall abundances of juvenile Mysis may facilitate enhanced fitness as a result of decreased predation rates and access to alternative resources at depths below $40 \mathrm{~m}$. The introduction of Mysis to Flathead Lake provided an abundant deep-water food source for lake trout that led to a subsequent expansion of the population and recent divergence into two distinct morphotypes that exhibit depth preference associated with distinctive diets, life histories, and morphologies. The deep-lake morphotype feeds heavily on Mysis, whereas the shallow-lake morphotype feeds opportunistically and are increasingly piscivorous with size (Stafford and others 2014). Enhanced predation pressure from deep-lake morphotypes with increasing depth may be driving the recent expansion of Mysis into the shallows. Juveniles that inhabit shallow waters of the littoral zone may be able to simultaneously decrease predation rates and capitalize on resources not present in the pelagic zone such as allochthonous organic matter and periphyton. Analysis of juvenile Mysis $(<6 \mathrm{~mm})$ gut contents from Flathead Lake revealed filamentous diatoms, pollen, and amorphous detritus (Chess and Stanford 1998), and studies from the Great Lakes have documented herbivory as a key feeding strategy of Mysis (Bowers and Grossnickle 1978; O'malley and others 2014).

Mysis demonstrated plasticity in life history characteristics over the period of record in Flathead Lake. In 1992 and 1993, populations exhibited a one-year life cycle, with release of a single cohort of juveniles in the spring that matured over the growing season, reproduced in the fall, and died the next summer following springtime brood release (see also Chess and Stanford 1998). A decade later (in 2012 and 2013), we detected the presence of a second brood of juveniles released later in the year. This desynchronization in timing of brood release is congruent with the notion of bottom-up influences on annual recruitment (Reznek 1980). When resources are abundant, YOY capitalize during the growing season to reach maturity by late summer (Polis and Strong 1996). Rather than carrying a brood over winter, release from resource limitation during the growing season provides energy for early reproduction and resources for the subsequent generation.

Although the mysid invasion has led to a dramatic increase in lake trout abundance (Ellis and others 2011), it appears that the Mysis still hold a strong top-down control on lower trophic levels and that a mysid-mediated trophic cascade leading to increased primary production still structures the food web in Flathead Lake. The daily movement of the mysid population from dark, deep waters upwards into metalimnetic waters at night and their return to the deep hypolimnion during the day may offer insight as to how they remain a topdown regulator and strong interactor, despite feeding a hungry population of lake trout. Daily vertical migration (DVM) could offset any regulatory impacts of predation by fish. On the other hand, the entire population likely does not migrate through the entire water column and those that remain near the bottom may be susceptible to deep-water predation by dwarf phenotype lake trout (Stafford and others 2014). Owing to the dramatic increase of lake trout and concomitant declines in native fishes, in 2008 managers initiated aggressive gill netting and targeted hook and line fishing in attempt to reduce predation by lake trout. How the on-going lake trout removal efforts may influence Mysis as strong interactors in the food web is uncertain. The high variation and overall increasing trends in abundance in the oscillation period may in fact be caused by lake trout removal, although given the highly plastic response of the Mysis over the course of the dataset examined here, this seems unlikely. In any case, the lake trout removal constitutes a lake-wide experiment in fisheries-mediated alteration of trophic structure and continued monitoring of the food web and biogeochemistry is critical.

Herein we have confirmed that Mysis has a profound and long-term regulatory role in the Flathead Lake food web as predicted by Ellis and others (2011). They act as strong interactors causing intense regulatory pressure on zooplankton, releasing grazing pressure on deep-water phytoplankton and increasing primary production. This study corroborates previously reported interactions between Mysis and the food web in Flathead Lake and demonstrates that ramifications of Mysis invasion are long lasting and continue. Including herein a decade of new data has allowed us to report that the Mysis population is not only increasing overall, but the population structure is also highly variable, demonstrating efficient use of resources and a wide connectedness to the other components of the food web, as well as the physical template created by the thermal structure of the lake (Figure 6). A novel examination of the spatial distribution of Mysis abundance has shown increasing use of shallower habitats indicating that Mysis behavior is dynamic. 
Changing size structure of Mysis over time reported herein offers new insight as to how Mysis life history is linked to increased variability in abundance. The trophic cascade reported by Ellis and others (2011) continues to regulate trophic dynamics in Flathead Lake. Here we not only corroborate that the trophic cascade is in effect by including 10 more years of abundance data to the previous study, but we also have added novel analysis investigating spatial dynamics and breeding life history to enhance our understanding of how Mysis remains a central focal species within the Flathead Lake food web. By increasing the use of shallower habitats and adapting to changing trophic dynamics via increased annual fecundity, Mysis appear poised to continue to act as a major regulator in Flathead Lake for the foreseeable future.

\section{ACKNOWLEDGEMENTS}

Funding for this work was provided by a large group of private landowners at Flathead Lake that has contributed annually to FLBS research on the lake. We thank the research and administrative staff at Flathead Lake Biological Station for their many years of hard work and for their assistance and contributions to this long-term study.

\section{OPEN ACCESS}

This article is distributed under the terms of the Creative Commons Attribution 4.0 International License (http://creativecommons.org/licenses/by/ 4.0/), which permits unrestricted use, distribution, and reproduction in any medium, provided you give appropriate credit to the original author(s) and the source, provide a link to the Creative Commons license, and indicate if changes were made.

\section{REFERENCES}

Beattie WD, Clancey PT. 1991. Effects of Mysis relicta on the zooplankton community and kokanee population of Flathead Lake, Montana. Am Fish Soc Symp 9:39-48.

Beeton AM. 1960. The Vertical Migration of Mysis relicta in Lakes Huron and Michigan. J Fish Res Board Can 17:517-39.

Beeton AM, Bowers JA. 1982. Vertical migration of Mysis relicta Lovén. Hydrobiologia 93:53-61.

Beeton AM, Gannon JE. 1991. Effect of environment on reproduction and growth of Mysis relicta. Trans Am Fish Soc Symp 9:144-8.

Berrill M, Lasenby DC. 1983. Life cycles of the fresh water mysid shrimp Mysis relicta reared at two temperatures. Trans Am Fish Soc 112:551-3.

Boscarino BT, Rudstam LG, Mata S, Gal G, Johannsson OE, Mills EL. 2007. The effects of temperature and predator-prey interactions on the migration behavior and vertical distribution of Mysis relicta. Limnol Oceanogr 52:1599-613.

Boscarino BT, Rudstam LG, Minson MA, Freund EE. 2010. Laboratory-derived light and temperature preferences of juvenile mysid shrimp, Mysis diluviana. J Great Lakes Res 36:699-706.

Bowers JA, Grossnickle NE. 1978. Herbivorous habits of Mysis relicta in Lake Michigan. Limnol Oceanogr 23:767-76.

Carpenter GF, Mansey EL, Watson NHF. 1974. Abundance and life history of Mysis relicta in St. Lawrence Great Lakes. J Fish Res Board Can 31:319-25.

Chess DW, Stanford JA. 1998. Comparative energetics and life cycle of the opossum shrimp (Mysis relicta) in native and nonnative environments. Freshw Biol 40:783-94.

Chess DW, Stanford JA. 1999. Experimental effects of temperature and prey assemblage on growth and lipid accumulation by Mysis relicta Lovén. Hydrobiologia 412:155-64.

Ellis BK et al. 2011. Long-term effects of a trophic cascade in a large lake ecosystem. Proc Natl Acad Sci 108:1070-5.

Ellis BK, Craft JA, Stanford JA. 2015. Long-term atmospheric deposition of nitrogen, phosphorus and sulfate in a large oligotrophic lake. PeerJ 3:e841.

Elser JJ, Goldman CR. 1991. Zooplankton effects on phytoplankton in lakes of contrasting trophic status. Limnol Oceanogr 36(1):64-90.

Fürst M. 1972. Life history, growth and reproduction in Mysis relicta Lovén. Rep Inst Freshw Res Drottningholm 11:1-41.

Gal G, Rudstam LG, Johannsson OE. 2004. Predicting Mysis relicta vertical distribution in Lake Ontario. Arch Hydrobiol 159:1-23.

Getis A, Ord JK. 1992. The analysis of spatial association by use of distance statistics. Geograph Anal 24:189-206.

Hakala I. 1978. Distribution, Population-Dynamics and Production of Mysis-Relicta (Loven) in Southern Finland. Ann Zool Fenn 15:243-58.

Johannsson OE, Bowen KL, Holeck KT, Walsh MG. 2011. Mysis diluviana population and cohort dynamics in Lake Ontario before and after the establishment of Dreissena spp., Cercopagis pengoi, and Bythotrephes longimanus. Can J Fish Aquat Sci 68:795-811.

Johnson JW, Lebreton JM. 2004. History and use of relative importance indices in organizational research. Org Res Methods 7:238-57.

Kjellberg G, Hessen DO, Nilssen JP. 1991. Life-history, growth and production of Mysis-relicta in the large, Fjord-type Lake Mjosa, Norway. Freshw Biol 26:165-73.

Lasenby DC, Langford RR. 1972. Growth, life history, and respirationof Mysis relicta in an arctic and temperate lake. J Fish Res Board Can 29:1701-8.

Li HW, Moyle PB. 1981. Ecological Analysis of Species Introductions into Aquatic Systems. Trans Am Fish Soc 110:77282.

Morgan MD. 1980. Life-history characteristics of 2 introduced populations of Mysis-relicta. Ecology 61:551-61.

O'malley BP, Bunnell DB. 2014. Diet of Mysis diluviana reveals seasonal patterns of omnivory and consumption of invasive species in offshore Lake Michigan. J Plankton Res 36:9891002.

Pennak RW. 1989. Fresh-water invertebrates of the United States: Protozoa to Mollusca. John Wiley $\&$ Sons, Inc., New York. 
Polis GA, Strong DR. 1996. Food web complexity and community dynamics. Am Nat 147:813-46.

Schindler DE, Carter JL, Francis TB, Lisi PJ, Askey PJ, Sebastian DC. 2012. Mysis in the Okanagan Lake food web: a time-series analysis of interaction strengths in an invaded plankton community. Aquat Ecol 46:215-27.

Spencer CN. 1991. Distribution and abundance of zooplankton and Mysis relicta in Flathead Lake. Flathead Lake Biological Station, The University of Montana. Report to the Montana Department of Fish, Wildlife and Parks.

Spencer CN, Ellis BK. 1998. Role of nutrients and zooplankton in regulation of phytoplankton in Flathead Lake (Montana, USA), a large oligotrophic lake. Freshw Biol 39:755-63.

Spencer CN, Potter DS, Bukantis RT, Stanford JA. 1999. Impact of predation by Mysis relicta on zooplankton in Flathead Lake, Montana, USA. J Plankton Res 21:51-64.
Stafford CP, McPhee MV, Eby LA, Allendorf FW. 2014. Introduced lake trout exhibit life history and morphological divergence with depth. Can J Fish Aquat Sci 71:10-20.

Teraguchi M, Hasler AD, Beeton AM. 1975. Seasonal changes in the response of I to illumination. Verhandlungen des Internationalen Verein Limnologie 19:2989-3000.

Vallentyne JR. 1957. Principles of modern limnology. Am Sci $45: 218-44$.

Wetzel RG, Likens GE. 2000. Limnological analyses. 3rd edn. New York: Springer.

Whited DC, Lorang MS, Harner MJ, Hauer FR, Kimball JS, Stanford JA. 2007. Climate, hydrologic disturbance, and succession: drivers of floodplain pattern. Ecology 88:940-53.

Winslow L, Read J, Woolway R, Brentrup J, Leach T, Zwart J. 2015. rLakeAnalyzer: Lake physics tools (R package). https:// cran.r-project.org/web/packages/rLakeAnalyzer/index.html. 